\title{
Genetic Diversity of Rabbit (Oryctolagus cuniculus) Population in South Eastern Nigeria Using Microsatellite Markers
}

\author{
A. I. Adeolu ${ }^{a}, *$ M. Wheto ${ }^{b}$, V. U. Oleforuh-Okoleh ${ }^{c}$, R. N. Nwose ${ }^{a}$, A. S. Adenaike ${ }^{b}$, A. Yakubu ${ }^{\text {, }}$, E. M. \\ Abiola $^{a}$, \& B. G. Mohammed ${ }^{a}$ \\ aDepartment of Agriculture, Animal Science Programme, Alex Ekwueme Federal University, \\ Ndufu-Alike, P.M. B. 1010, Abakaliki, Ebonyi State, Nigeria \\ bDepartment of Animal Breeding and Genetics, College of Animal Science and Livestock Production, Federal \\ University of Agriculture, Abeokuta, P. M. B. 2240 Ogun State, Nigeria \\ 'Department of Animal Science, Rivers State University of Science and Technology, \\ Nkpolu-Oroworukwo, P.M.B. 5080, Port Harcourt, Rivers State, Nigeria \\ dDepartment of Animal Science, Faculty of Agriculture, Nasarawa State University, \\ Keffi, Shabu-Lafia Campus, P.M.B. 135, Lafia, Nigeria \\ *Corresponding Author: adeolufunai2012@gmail.com \\ (Received 13-08-2020; Revised 11-01-2021; Accepted 02-02-2021)
}

\begin{abstract}
A study was conducted to estimate the diversity that exists among three rabbit populations adapted to the South-Eastern part of Nigeria. Blood samples were collected from 75 matured, mixedsex, and unrelated three rabbit breeds selected across the zone. Eight microsatellites (Sol30, Sol33, and Sol44, Sat3, Sat7, Sat8, Sat12, and INRA) markers were used for the study. These microsatellites were uniformly distributed among rabbit genomes for genotyping. Subsequently, genetic variability within and between breeds was calculated. Allelic frequencies and Hardy-Weinberg equilibriums as well as Analysis of Molecular Variance, were also estimated using GenAlEX 6.41 software. Discriminant Analysis of Principal Components (DAPC) for the population structure of the rabbit breeds was performed in $R$ v.3.5.0 using the $R$ package adegenet. All the 8 loci amplified in this study were found to be $\mathbf{1 0 0} \%$ polymorphic, the observed allele sizes and their frequencies for the microsatellite markers in every three breeds showed that the highest frequency was 0.330 for the allele with the size of 470bp at Sol33 locus in New Zealand White (NZW) rabbits. The Nei's genetic identities and distances between Chinchilla (CHI) and Dutch (DUT), CHI and NZW, DUT and NZW obtained in this study were $[0.173,0.185$, and 0.189$]$ and $[1.753,1.689$, and 1.666] respectively. The dendrogram and biplot revealed that the three breeds were identified at two separate clusters. In addition, the admixture level of an individual rabbit among the three breeds indicated that the breeds were not pure and also the existence of more polymorphism within the breed than among the breed diversity.
\end{abstract}

Keywords: genetic diversity; rabbit; breeds; microsatellite markers

\section{INTRODUCTION}

Rabbit is a prolific, fast-growing, and high fecundity; thus, rabbit production is one of the animal protein sources in developing countries like Nigeria. Rabbit meat is rich in micronutrients such as iron, zinc, iodine, and vitamin $\mathrm{B}_{12}$ and low in cholesterol and sodium level (Adeolu et al., 2020). Hence, its consumption was recommended for alleviating hidden hunger in women of reproductive age and infants within 1000 days (window period) of life. Despite some of the nutritional and health benefits of eating rabbit meat, rabbits exhibit exceptional phenotype diversity, which could serve great commercial benefits and also serve as important animal models in biomedical research (Carneiro et al., 2011).

These attributes have brought about increased clamor and excitement for upgrading available rabbit breeds for high reproductive and growth potentials
(FAO, 2004). For upgrading to be effective, information concerning economic traits and their diversities needs to be examined and documented under the prevailing environmental conditions. Information on the degree of genetic variation and diversity changes of adapted rabbits over time will contribute to efficient conservation, maintenance, and rational utilization of germplasm resources that determine future breeding strategies for the assessment of useful genes from divergent germplasm.

Domestic rabbits are classified into different breeds based on the color, biometric traits, and origin (Sanford, 1996), but there is a need to differentiate between these rabbit breeds with the aid of molecular markers because they are more abundant, ubiquitous, hypervariable in nature, and evenly distributed along the chromosomes. Characterization at the molecular level is carried out to explore the genetic diversity between and within livestock populations and also to determine the genetic 
relationship among the different populations (Rahimi et al., 2015). Studies (Chantry-Darmon et al., 2006; Grimal et al., 2012; El-Aksher et al., 2016) have shown the importance of microsatellites in generating the information necessary for planning crossbreeding and selection of genotypes in genetic breeding programs in rabbits.

The historical record of rabbit rearing in Nigeria shows that rabbits are not native to Nigeria and South Eastern Zone in particular. Many breeds were introduced into the country with the advent of the slave trade and European invasion into Africa, and hence, the genetic information of those adapted to various geopolitical zones is scanty or not available. In the present study, we sampled three populations of adapted rabbits in the South Eastern Zone of Nigeria to evaluate the degree of genetic variability over a period of adaptation using eight (8) microsatellite markers that exploit the genetic relationship among rabbit populations based on certain parameters.

\section{MATERIALS AND METHODS}

\section{Experimental Animals}

A total of 75 matured, mixed-sex and unrelated rabbits, Dutch (DUT), Chinchilla (CHI), and New Zealand White (NZW) from research and teaching farm of five (5) Universities within South Eastern Nigeria were drawn from the entire population to form the samples. These include 5 samples each per breed from Michael Okpala University of Agriculture, Umudike (MOUAU), Nnamdi Azikwe University, Akwa (UNIZIK), Ebonyi State University, Abakaliki (EBSU), University of Nigeria, Nsukka (UNN), and Federal University of Science and Technology, Owerri (FUTO). Animal ethics and welfare certificate/approval was obtained from the University Research Ethics Committee of Alex Ekwueme Federal University Ndufu-Alike [AE-FUNAI] with reference No.: FUNAI/SEN/EBC/17/VOL. 1/22.

\section{Blood Collection and DNA Extraction}

Approximately 1-2 mL of blood was collected aseptically from each experimental animal and put into EDTA bottle with the aid of a needle and syringe. Genomic DNA was extracted using Qiagen DNA extraction kits with strict compliance to the manufacturer protocols. Quantification of DNA yield and assessment of quality were done using a Nanodrop ${ }^{\mathrm{TM}}$ spectrophotometer and $1 \%$ agarose gel electrophoresis, respectively.

\section{Genotyping of Microsatellite Markers}

A total of eight (8) microsatellite markers (Sol30, Sol33, and Sol44, Sat3, Sat7, Sat8, Sat12, and INRA) uniformly distributed across the rabbit genomes as reported by El-Aksher et al. (2016) were used for this study. PCR amplification was carried out in a thermocycler. The $25 \mu \mathrm{L}$ PCR reaction mix was prepared in PCR tubes containing $2 \mu \mathrm{L}$ of DNA template, $1 \mu \mathrm{L}$ each of forward and reverse primers, $12.5 \mu \mathrm{L}$ of $2 \mathrm{X}$ PCR Master mix, and $8.5 \mu \mathrm{L}$ of Nuclease free water. The amplification reaction was as follows: Initial denaturation at $94^{\circ} \mathrm{C}$ for 5 minutes, 35 cycles of denaturation at $94^{\circ} \mathrm{C}$ for 1 minute, annealing at $53.2^{\circ} \mathrm{C}$ to $60.0^{\circ} \mathrm{C}$ for 1 minute, extension at $72^{\circ} \mathrm{C}$ for 1 minute, and followed by the final extension at $72^{\circ} \mathrm{C}$ for 10 minutes. The resulting amplicons were visualized using $1.5 \%$ agarose to separate the PCR products into different sizes at 100 Volts for 1 hour using DNA ladder of $100 \mathrm{bp}$. The gel was stained with ethidium bromide, the resulting band was viewed under transilluminator and genotyped using GelAnalyser.

Microsatellite data analysis. Genotypic, allelic frequencies, and Hard-Weinberg equilibriums as well as Analysis of Molecular variance, were estimated using GenAlEX 6.41 software. To investigate the population genomic structure of rabbit breeds, Discriminant Analysis of Principal Components (DAPC) was performed in R v.3.5.0 (R Development Core Team 2008), using the $\mathrm{R}$ package adegenet.

\section{RESULTS}

\section{Genetic Differentiation Among and Within the Population}

From the summary of the Analysis of Molecular Variance, AMOVA in Table 1, the genetic differentiation measured among population and individual of the total genetic variance were $1 \%$ and $4 \%$ respectively, while $96 \%$ of the genetic variation was attributed to withinpopulation genetic diversity.

\section{Allele Frequencies for the Microsatellite Loci Across the Three Breeds}

The observed allele sizes and their frequencies for the microsatellite markers in each breed's population in Figure 1 show that the highest frequency was 0.330 for the allele with the size of $470 \mathrm{bp}$ at Sol33 locus in New Zealand White (NZW) rabbits while the lowest (0.083) was common to Sol44 in each breed within a population. Other allele frequency results obtained from the interpretation of Figure 1 for the microsatellite loci across the three breeds were mostly polymorphic.

\section{The Mean $\left(\mathrm{N}_{\mathrm{a}}\right)$ and Effective $\left(\mathrm{N}_{\mathrm{e}}\right)$ Number of Alleles at Various Loci Across Population}

The mean number of alleles $\left(\mathrm{N}_{\mathrm{a}}\right)$ observed in the overall population of three rabbit breeds in the present study was 10.208 (Table 2). In the subpopulation, Dutch (DUT) breed had the highest $\mathrm{N}_{\mathrm{a}}$ of 10.375 when com-

Table 1. Summary AMOVA table

\begin{tabular}{lcccc}
\hline Source & Df & MS & Est. Var. & $\%$ \\
\hline Among population & 2 & 4.361 & 0.027 & $1 \%$ \\
Among individual & 15 & 4.033 & 0.142 & $4 \%$ \\
Within individual & 18 & 3.750 & 3.750 & $96 \%$ \\
Total & 35 & & 3.919 & $100 \%$ \\
\hline
\end{tabular}

Note: $\mathrm{Df}=$ Degree of freedom; MS= Mean square; Est.Var.= Estimated variance. 


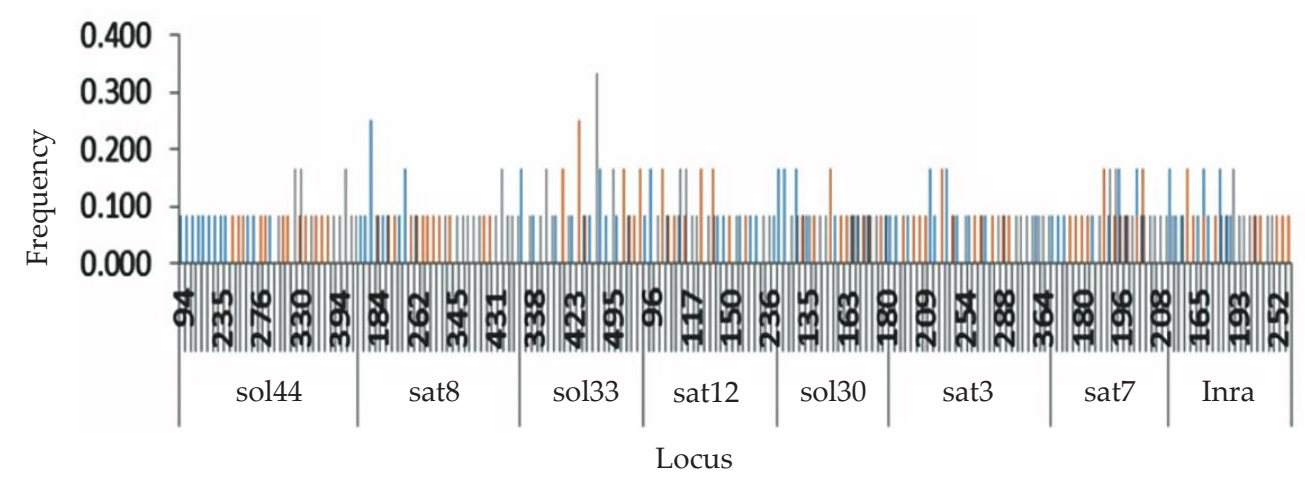

Figure 1. Allele frequencies for all the microsatellite markers across the three breeds. $\mathrm{E}=$ Chinchilla; = Dutch ; $=$ = New Zealand.

Table 2. Results of parameters analyzed at various microsatellite loci across the three breeds

\begin{tabular}{|c|c|c|c|c|c|c|c|c|c|}
\hline Population & Locus & $\mathrm{N}$ & $\mathrm{N}_{\mathrm{a}}$ & $\mathrm{N}_{\mathrm{e}}$ & I & $\mathrm{H}_{\mathrm{o}}$ & $\mathrm{H}_{\mathrm{e}}$ & $\mathrm{uH}_{\mathrm{e}}$ & $\mathrm{F}$ \\
\hline \multicolumn{10}{|l|}{$\mathrm{CHI}$} \\
\hline & Sol30 & 6 & 9.000 & 8.000 & 2.138 & 0.833 & 0.875 & 0.955 & 0.048 \\
\hline & Sol33 & 6 & 10.000 & 9.000 & 2.254 & 0.667 & 0.889 & 0.970 & 0.250 \\
\hline & Sol44 & 6 & 12.000 & 12.000 & 2.485 & 1.000 & 0.917 & 1.000 & -0.091 \\
\hline & Sat3 & 6 & 10.000 & 9.000 & 2.254 & 1.000 & 0.889 & 0.970 & -0.125 \\
\hline & Sat7 & 6 & 10.000 & 9.000 & 2.254 & 1.000 & 0.889 & 0.970 & -0.125 \\
\hline & Sat8 & 6 & 9.000 & 7.200 & 2.095 & 1.000 & 0.861 & 0.939 & -0.161 \\
\hline & Sat12 & 6 & 11.000 & 10.286 & 2.369 & 0.833 & 0.903 & 0.985 & 0.077 \\
\hline & Inra & 6 & 9.000 & 8.000 & 2.138 & 1.000 & 0.875 & 0.955 & -0.143 \\
\hline & Mean \pm SE & $6.000 \pm 0.000$ & $10.000 \pm 0.378$ & $9.061 \pm 0.532$ & $2.248 \pm 0.046$ & $0.917 \pm 0.045$ & $0.887 \pm 0.006$ & $0.968 \pm 0.007$ & $-0.034 \pm 0.051$ \\
\hline \multicolumn{10}{|l|}{ DUT } \\
\hline & Sol30 & 6 & 11.000 & 10.286 & 2.369 & 1.000 & 0.903 & 0.985 & -0.108 \\
\hline & Sol33 & 6 & 7.000 & 6.000 & 1.864 & 1.000 & 0.833 & 0.909 & -0.200 \\
\hline & Sol44 & 6 & 12.000 & 12.000 & 2.485 & 1.000 & 0.917 & 1.000 & -0.091 \\
\hline & Sat3 & 6 & 11.000 & 10.286 & 2.369 & 1.000 & 0.903 & 0.985 & -0.108 \\
\hline & Sat7 & 6 & 10.000 & 9.000 & 2.254 & 1.000 & 0.889 & 0.970 & -0.125 \\
\hline & Sat8 & 6 & 12.000 & 12.000 & 2.485 & 1.000 & 0.917 & 1.000 & -0.091 \\
\hline & Sat12 & 6 & 9.000 & 8.000 & 2.138 & 1.000 & 0.875 & 0.955 & -0.143 \\
\hline & Inra & 6 & 11.000 & 10.286 & 2.369 & 1.000 & 0.903 & 0.985 & -0.108 \\
\hline & Mean \pm SE & $6.000 \pm 0.000$ & $10.375 \pm 0.596$ & $9.732 \pm 0.716$ & $2.292 \pm 0.073$ & $1.000 \pm 0.000$ & $0.892 \pm 0.010$ & $0.973 \pm 0.011$ & $-0.122 \pm 0.013$ \\
\hline \multicolumn{10}{|l|}{ NZW } \\
\hline & Sol30 & 6 & 12.000 & 12.000 & 2.485 & 1.000 & 0.917 & 1.000 & -0.091 \\
\hline & Sol33 & 6 & 7.000 & 5.143 & 1.792 & 0.333 & 0.806 & 0.879 & 0.586 \\
\hline & Sol44 & 6 & 9.000 & 8.000 & 2.138 & 0.833 & 0.875 & 0.955 & 0.048 \\
\hline & Sat3 & 6 & 12.000 & 12.000 & 2.485 & 1.000 & 0.917 & 1.000 & -0.091 \\
\hline & Sat7 & 6 & 10.000 & 9.000 & 2.254 & 1.000 & 0.889 & 0.970 & -0.125 \\
\hline & Sat8 & 6 & 11.000 & 10.286 & 2.369 & 1.000 & 0.903 & 0.985 & -0.108 \\
\hline & Sat12 & 6 & 10.000 & 9.000 & 2.254 & 1.000 & 0.889 & 0.970 & -0.125 \\
\hline & Inra & 6 & 11.000 & 10.286 & 2.369 & 1.000 & 0.903 & 0.985 & -0.108 \\
\hline & Mean \pm SE & $6.000 \pm 0.000$ & $10.250 \pm 0.590$ & $9.464 \pm 0.796$ & $2.268 \pm 0.080$ & $0.896 \pm 0.083$ & $0.887 \pm 0.013$ & $0.968 \pm 0.014$ & $-0.002 \pm 0.086$ \\
\hline & GrandMean \pm SE & $6.000 \pm 0.000$ & $10.208 \pm 0.295$ & $9.419 \pm 0.385$ & $2.269 \pm 0.038$ & $0.938 \pm 0.031$ & $0.889 \pm 0.005$ & $0.970 \pm 0.006$ & $-0.052 \pm 0.034$ \\
\hline
\end{tabular}

Note: $\mathrm{N}_{\mathrm{a}}=$ Mean number of alleles; $\mathrm{Ne}=$ Effective number of alleles; I= Shannon's Information Index; $\mathrm{H}_{\mathrm{o}}=$ Observed Heterozygosity; $\mathrm{H}_{\mathrm{e}}=$ Expected Heterozygosity; $\mathrm{uH}_{\mathrm{e}}=$ Unbiased Expected Heterozygosity; $\mathrm{F}=$ Fixation Index; Mean $\mathrm{H}_{\mathrm{e}}=$ Average $\mathrm{H}_{\mathrm{e}}$ across the populations; Mean $\mathrm{H}_{\mathrm{o}}=$ Average $\mathrm{H}_{\mathrm{o}}$ across the populations; $\mathrm{H}_{\mathrm{t}}=$ Total Expected Heterozygosity; $\mathrm{CHI}=$ Chinchilla; DUT= Dutch; $\mathrm{NZW=}$ New Zealand White.

pared to the Chinchilla $(\mathrm{CHI}),\left(\mathrm{N}_{\mathrm{a}}=10.000\right)$, and NZW $\left(\mathrm{N}_{\mathrm{a}}=10.250\right)$.

The number of effective alleles observed $\left(\mathrm{N}_{\mathrm{e}}\right)$ among eight loci within the three breeds ranged from 7-12. Sol33 locus produced the least number of alleles $\left(\mathrm{N}_{\mathrm{e}}=7\right)$ in DUT and NZW, while the highest $\left(\mathrm{N}_{\mathrm{e}}=12\right)$ was made by Sol44 locus (in CHI and DUT), Sol30, and Sat3 loci (in NZW), and Sat8 locus (in DUT).

The mean effective number of alleles $\left(\mathrm{N}_{\mathrm{e}}\right)$ in population across various loci were 9.061, 9.732, and 9.464 in CHI, DUT, and NZW breeds, respectively, and ranged from 5.143 at Sol33 locus in NZW to 12.000 at Sol44 lo- 
cus in CHI, Sol44 and Sat8 loci in DUT, and Sol30 and Sat3 in NZW.

\section{The Observed $\left(\mathrm{H}_{\mathrm{o}}\right)$, Expected $\left(\mathrm{H}_{\mathrm{e}}\right)$, and Unbiased Expected $\left(\mathrm{uH}_{\mathrm{e}}\right)$ Heterozygosity at Various Loci Across Population}

The results of these parameters are presented in Table 2. The overall mean of observed heterozygosity $\left(\mathrm{H}_{\mathrm{o}}\right)$ was 0.938 and ranged from 0.333 to 1.000 . The expected heterozygosity $\left(\mathrm{H}_{\mathrm{e}}\right)$ for all loci studied averaged 0.889 , while the mean $\mathrm{H}_{\mathrm{e}}$ recorded for $\mathrm{CHI}$, DUT, and NZW breeds were $0.887,0.892$, and 0.887 , respectively. The unbiased expected heterozygosity $\left(\mathrm{uH}_{\mathrm{e}}\right)$ ranged from 0.939 to 1.000 in CHI, 0.909 to 1.000 in DUT, and 0.879 to 1.000 in NZW (Table 2).

\section{Hardy-Weinberg Equilibrium (HWE) at Various Loci Across Population}

Departure from Hardy-Weinberg equilibrium (HWE) was tested across the three rabbit breeds within the loci studied. No significant deviation was observed except for the Sol33 locus, which was found to be significantly deviating from the HWE in NZW rabbits (Table $3)$.

\section{Genetic Differentiation by Reduction in Heterozygosity Due to Inbreeding}

The F-statistics $\left(\mathrm{F}_{\mathrm{IS}}, \mathrm{F}_{\mathrm{IT}}\right.$ and $\left.\mathrm{F}_{\mathrm{ST}}\right)$ presented in Table 4 showed the reduction in heterozygosity at various loci across the population studied. The mean values

Table 3. Chi-Square ( $\chi 2)$ values for testing Hardy-Weinberg Equilibrium (HWE) across the populations over each locus

\begin{tabular}{|c|c|c|c|c|c|}
\hline Population & Locus & DF & $\chi^{2}$ & Probability & Significance \\
\hline \multirow[t]{8}{*}{$\mathrm{CHI}$} & Sol30 & 36 & 36.000 & 0.469 & ns \\
\hline & Sol33 & 45 & 54.000 & 0.168 & ns \\
\hline & Sol44 & 66 & 66.000 & 0.477 & ns \\
\hline & Sat3 & 45 & 54.000 & 0.168 & ns \\
\hline & Sat7 & 45 & 42.000 & 0.600 & ns \\
\hline & Sat8 & 36 & 42.000 & 0.227 & ns \\
\hline & Sat12 & 55 & 60.000 & 0.299 & ns \\
\hline & Inra & 36 & 42.000 & 0.227 & ns \\
\hline \multirow[t]{8}{*}{ DUT } & Sol30 & 55 & 54.000 & 0.513 & ns \\
\hline & Sol33 & 21 & 30.000 & 0.092 & ns \\
\hline & Sol44 & 66 & 66.000 & 0.477 & ns \\
\hline & Sat3 & 55 & 54.000 & 0.513 & ns \\
\hline & Sat7 & 45 & 42.000 & 0.600 & ns \\
\hline & Sat8 & 66 & 66.000 & 0.477 & ns \\
\hline & Sat12 & 36 & 36.000 & 0.469 & ns \\
\hline & Inra & 55 & 54.000 & 0.513 & ns \\
\hline \multirow[t]{8}{*}{ NZW } & Sol30 & 66 & 66.000 & 0.477 & ns \\
\hline & Sol33 & 21 & 36.000 & 0.022 & * \\
\hline & Sol44 & 36 & 48.000 & 0.087 & ns \\
\hline & Sat3 & 66 & 66.000 & 0.477 & ns \\
\hline & Sat7 & 45 & 42.000 & 0.600 & ns \\
\hline & Sat8 & 55 & 54.000 & 0.513 & ns \\
\hline & Sat12 & 45 & 54.000 & 0.168 & ns \\
\hline & Inra & 55 & 54.000 & 0.513 & ns \\
\hline
\end{tabular}

Note: $\mathrm{CHI}=$ Chinchilla; DUT= Dutch; NZW=New Zealand White; DF= degree of freedom, ns= not significant, ${ }^{*}=$ significant at $\mathrm{p}<0.05$.

Table 4. F-Statistics and estimates of $\mathrm{N}_{\mathrm{m}}$ over-all population for each locus

\begin{tabular}{|c|c|c|c|c|}
\hline Locus & $\mathrm{F}_{\text {IS }}$ & $\mathrm{F}_{\mathrm{IT}}$ & $\mathrm{F}_{\mathrm{ST}}$ & $\mathrm{N}_{\mathrm{m}}$ \\
\hline Sol30 & -0.052 & -0.003 & 0.046 & 5.196 \\
\hline Sol33 & 0.209 & 0.294 & 0.108 & 2.068 \\
\hline Sol44 & -0.046 & 0.021 & 0.064 & 3.656 \\
\hline Sat3 & -0.108 & -0.040 & 0.061 & 3.849 \\
\hline Sat7 & -0.125 & -0.071 & 0.048 & 4.966 \\
\hline Sat8 & -0.119 & -0.042 & 0.069 & 3.366 \\
\hline Sat12 & -0.063 & 0.005 & 0.063 & 3.692 \\
\hline Inra & -0.119 & -0.062 & 0.051 & 4.669 \\
\hline Mean \pm SE & $-0.053 \pm 0.039$ & $0.013 \pm 0.042$ & $0.064 \pm 0.007$ & $3.933 \pm 0.357$ \\
\hline
\end{tabular}

Note: $\mathrm{F}_{\mathrm{IS}}=$ reduction in heterozygosity due to inbreeding within each population; $\mathrm{F}_{\mathrm{IT}}=$ reduction in heterozygosity due to total inbreeding for each locus; $\mathrm{F}_{\mathrm{ST}}=$ Genetic differentiation among the population; $\mathrm{N}_{\mathrm{m}}=$ Limited gene flow among the population. 
for $\mathrm{F}_{\text {IS }}$ and $\mathrm{F}_{\mathrm{IT}}$ were -0.053 and 0.013 , respectively. $\mathrm{F}_{\mathrm{ST}}$ value ranged from 0.046 at locus Sol30 and 0.108 at locus Sol33, and it averaged 0.064 . The mean $\mathrm{F}_{\mathrm{ST}}(0.064)$ can be translated to $6.4 \%$ and $93.6 \%$ for among/inter-population and within/intra-population variation respectively. The mean level of gene flow $(\mathrm{Nm})$ among the population was estimated to be 3.933, ranging from 2.068 to 5.196 (Table 4). The pairwise $\mathrm{F}_{\mathrm{ST}}$ values among the three populations were also ranged from 0.048 to 0.049 (Table $5)$.

\section{Genetic Identity and Distance Among Populations}

To further clarify the gene differentiation among different populations, Nei's pairwise (Nei, 1978) genetic similar (identity) and distance coefficients were assessed (Table 6). Genetic similar coefficients varied from 0.173 to 0.189 with an average of 0.182 . The Nei's genetic distances between CHI and DUT, CHI and NZW, as well as DUT and NZW obtained in this study, were 1.753, 1.689, and 1.666 , respectively.

In order to further illustrate the relationships among populations, a dendrogram based on Nei's genetic similarity, clustered the three populations into two major groups (Figure 2) with the CHI breed in a distinct cluster from the DUT and NZW breeds showing the considerable genetic distance between the chinchilla breed and other two breeds.

Discriminant analysis of Principal Components (DAPC) shows three clusters identified (Figure 4). Linear discriminant 1 separated the Dutch breed from the other two breeds, while linear discriminant 2 isolated New Zealand White from the other two breeds.

\section{DISCUSSION}

The higher value of within-population genetic diversity (Table 1) obtained in the present study is similar to the work of El-Aksher et al. (2016), and such results may largely be attributed to existing random breeding systems in the study area. This usually resulted in frequent gene flow among individuals and increases the chance of gene recombination.

In reference to Figure 1, all the 8 loci amplified in this study were found to be $100 \%$ polymorphic in all the three breeds, which was consistent with the find-

Table 5. Pairwise population of $\mathrm{F}_{\mathrm{ST}}$ values

\begin{tabular}{lccc}
\hline & Chinchilla (CHI) & Dutch (DUT) & New Zealand White (NZW) \\
\hline Chinchilla (CHI) & 0.000 & & \\
Dutch (DUT) & 0.049 & 0.000 & 0.000 \\
New Zealand White (NZW) & 0.049 & 0.048 & \\
\hline
\end{tabular}

Table 6. Pairwise population matrix of Nei's genetic distance and identity

\begin{tabular}{lccc}
\hline & Chinchilla (CHI) & Dutch (DUT) & New Zealand White (NZW) \\
\hline Chinchilla (CHI) & 0.000 & 0.173 & 0.185 \\
Dutch (DUT) & 1.753 & 0.000 & 0.189 \\
New Zealand White (NZW) & 1.689 & 1.666 & 0.000 \\
\hline
\end{tabular}

Note: Upper diagonal - Genetic Identity, Lower diagonal - Genetic Distance

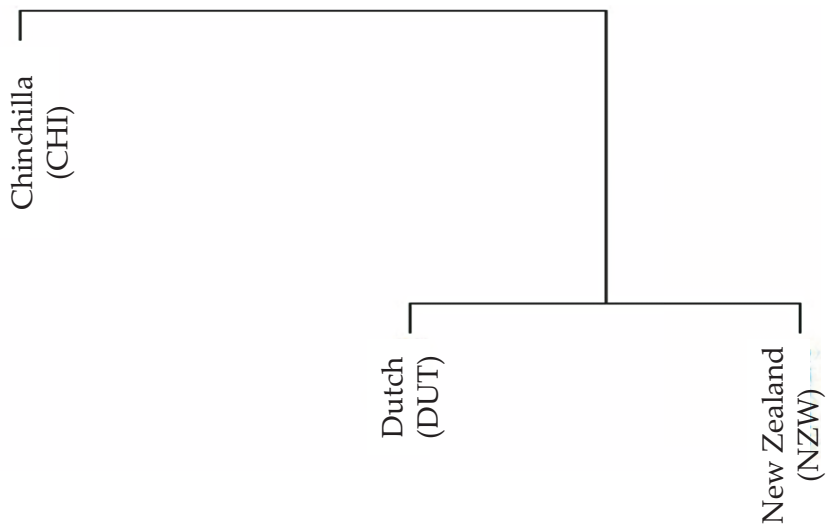

Figure 2. Dendrogram showing genetic relationships among the three rabbit breeds based on Fixation indices.

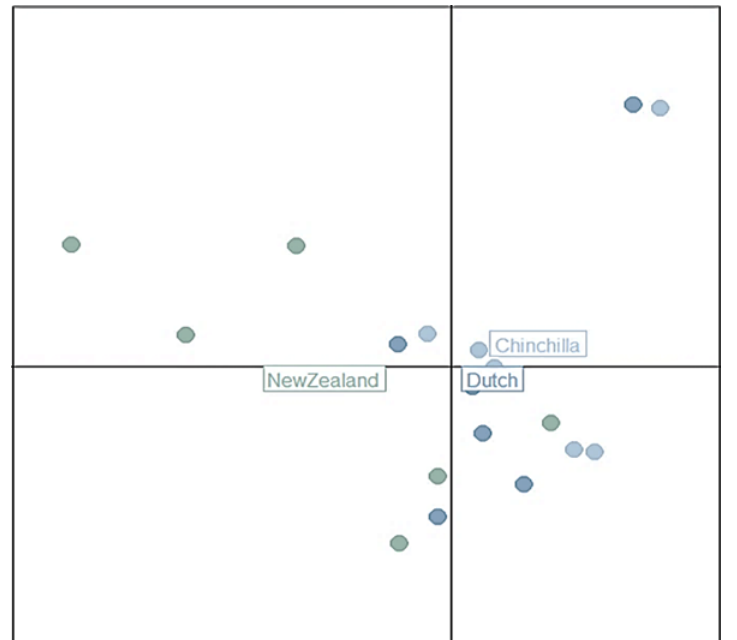

Figure 3. Biplot showing genetic relationships among the three rabbit breeds. 


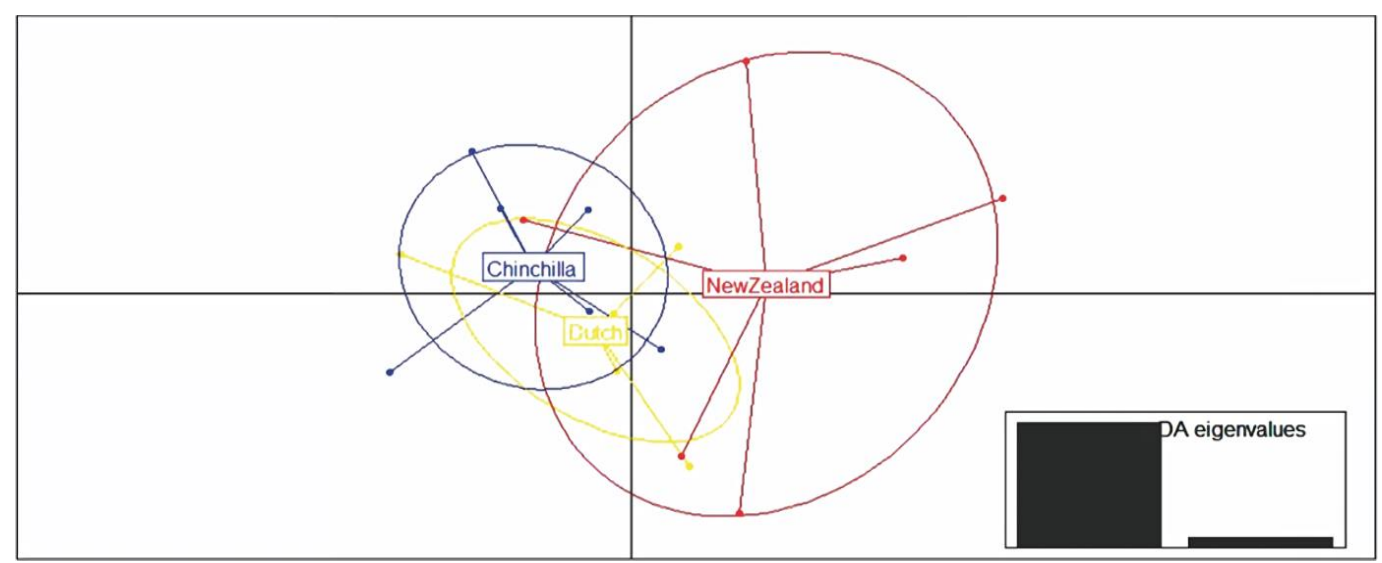

Figure 4. Discriminant analysis of Principal Components (DAPC) where the horizontal axis represents the first linear discriminant, the vertical axis represents the second linear discriminant.

ings of Grimal et al. (2012) in Egyptian and Spanish rabbits, Thimmayya \& Buskirk (2012) in pygmy rabbits, Ben-Larbi et al. (2014) in Tunisian indigenous rabbits, El-Aksher et al. (2016) in Egypt Moshtohor line rabbits, and Kannegundla et al. (2018) in India rabbits. However, this result was higher than $81 \%$ polymorphic of the utilized microsatellites in European rabbits, as reported by Chantry-Darmon et al. (2006). El-Aksher et al. (2016) recommended high polymorphic loci (microsatellites) in the determination of the genetic structure and assessment of the gene pattern flow in any population.

The Mean number of alleles $\left(\mathrm{N}_{\mathrm{a}}\right)$ obtained in the subpopulation for CHI, DUT, and NZW were higher than the findings of Omotoso et al. (2019) in four rabbit breeds reared in South Western Nigeria. Authors deduced high $\mathrm{N}_{\mathrm{a}}$ as an indication of great allelic diversity which could have been influenced by crossbreeding or admixture among the population studied.

The marker(s) associated with range (7-12) of the mean effective number of alleles $\left(\mathrm{N}_{\mathrm{e}}\right)$ across various loci reported in the present study are usually referred to least and most polymorphic marker(s), respectively. This range also showed that the markers used for the study were appropriate because their polymorphisms were higher than the minimum of 5 alleles (FAO, 2011) required for estimation of genetic diversity within an animal population through microsatellite markers. Therefore, a minimum of 7 alleles per locus indicated amplification and confirmed enough alleles to estimate the genetic diversity among the three genetic groups studied (Kannegundla et al., 2018). The range of $\mathrm{N}_{\mathrm{e}}$ recorded in the present study was higher than the range of 3-7 reported by Wu et al. (2010). However, El-Aksher et al. (2016) and Kannegundla et al. (2018) reported a closed similar range of 4-10 and 5-11, respectively. According to Frankham et al. (2002), the $\mathrm{N}_{\mathrm{e}}$ observed over a range of loci for different breeds are also known as the allelic diversity, and it is an important parameter of genetic variation. The overall means $\mathrm{N}_{\mathrm{e}}$ across genotypes are relatively higher than the mean $\mathrm{N}_{\mathrm{e}}$ of 3.89 reported by El-Aksher et al. (2016) in Moshtohor line rabbits of Egypt, 4.156 reported by Abdel-Kafy et al. (2018) in native rabbits in Middle Egypt, as well as 6.728 and
6.874 reported by Kannegundla et al. (2018) in Soviet Chinchilla and Californian White rabbits, respectively.

The values obtained for expected heterozygosity $\left(\mathrm{H}_{\mathrm{e}}\right)$ are comparable and consistent to the findings of Kannegundla et al. (2018) in Indian rabbits (0.842-0.849), Wu et al. (2010) in American Rex Rabbit (0.675-0.820), and El-Aksher et al. (2016) in Egypt Moshtohor line rabbits (0.66-0.88), but higher than the findings of Thimmayya \& Buskirk (2012) in Pygmy rabbits (0.540.60), Ben-Larbi et al. (2014) in indigenous Tunisian rabbit (0.39-0.58), and Rabie et al. (2020) in five Egyptian rabbit breeds (0.20-0.65). Generally, the observed heterozygosity $\left(\mathrm{H}_{\mathrm{o}}\right)$ in all loci were higher than $\mathrm{H}_{\mathrm{e}}$ (except at Sol30, Sol33, and Sat12 in CHI and Sol44 and Sol33 in NZW) This result was contrary to the findings of El-Aksher et al. (2016) and Grimal et al. (2012) who respectively, reported $\mathrm{H}_{\mathrm{o}}$ lower than $\mathrm{H}_{\mathrm{e}}$ in 14 loci out of 16 used and in four Egyptian rabbit breeds and NZW. The authors conclusively affirmed $\mathrm{H}_{\mathrm{e}}$ as the most parameters widely used to measure the genetic diversity across and within the populations.

Similarly, the results obtained for unbiased expected $\left(\mathrm{uH}_{\mathrm{e}}\right)$ heterozygosity at various loci across populations were also higher than the ranges of 0.747 to 0.913 in Soviet Chinchilla and 0.809 to 0.915 in Californian White as reported by Kannegundla et al. (2018).

Chi-Square tests showed that the allele frequencies are in Hardy-Weinberg equilibrium ( $p>0.05)$ across populations studied over each locus. The implication is that the populations of rabbits used may be randomly bred due to the uncontrolled breeding system usually practiced by farmers in the study area. Zenger et al. (2003) used seven SAT microsatellite loci in 252 wild rabbits from five populations across Australia as against data from Europe and discovered that deviations $(p>0.05)$ from HWE were non-significant in any of the Australian data. Non-significant deviations from HWE showed the existence of random breeding among three breeds' rabbit population, and allelic frequencies might remain the same except the population is influenced by evolutionary forces. Exception observed at locus Sol33 in NZW rabbits was an indication of selection at this locus, as observed by Kannegundla et al. (2018). 


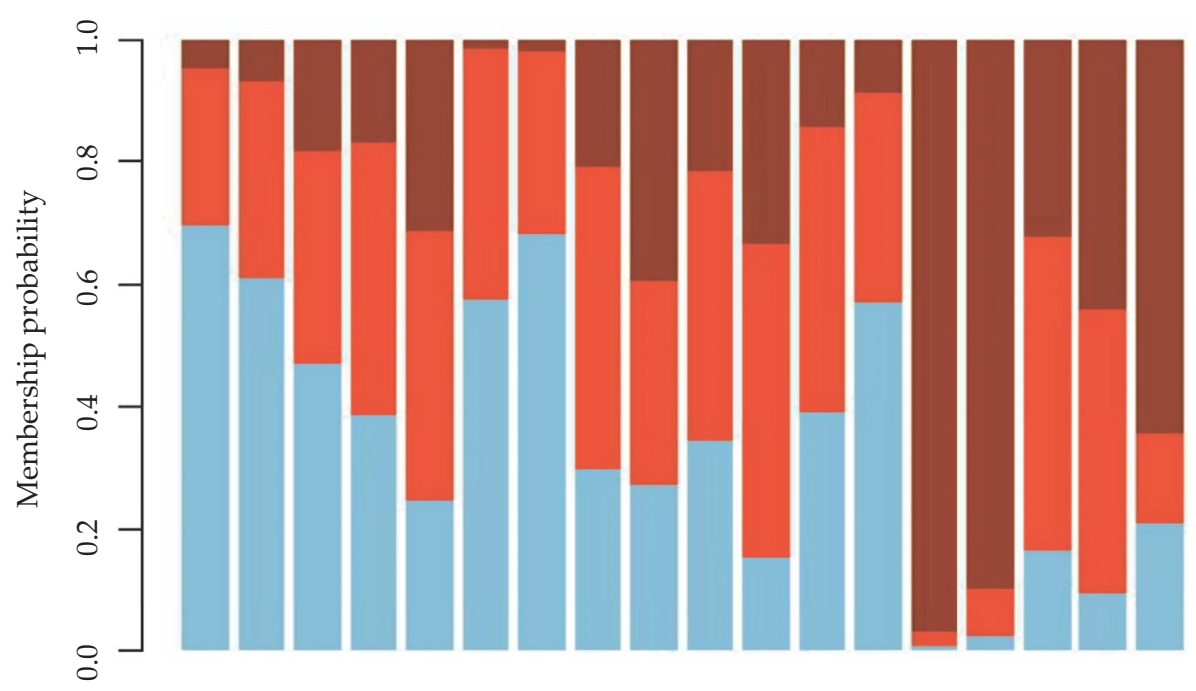

Figure 5. Admixture level of individual rabbit among the three breeds, $\square=$ Chinchilla; $\square=$ Dutch ; $=$ New Zealand.

The reduction in heterozygosity due to inbreeding $\left(\mathrm{F}_{\mathrm{IS}^{\prime}}, \mathrm{F}_{\mathrm{IT}}\right.$ and $\left.\mathrm{F}_{\mathrm{ST}}\right)$ was developed by Wright (1951) for testing the genetic differentiation among populations and also to summarize the genetic structure of a population and its subpopulations. The negative values for $F_{I S}$ and $F_{\text {IT }}$ at Sat8, Sol30, Sat3, Sat7, and Inra loci indicated the occurrence of heterozygote genotypes at a proportion higher than the homozygous genotypes at all loci. Such a negative value for $\mathrm{F}_{\text {IS }}$ corroborated -0.114 obtained by Wu et al. (2010).

The mean $\mathrm{F}_{\mathrm{ST}}(0.064)$ obtained in the present study was higher than 0.04 and 0.0479 , respectively, reported by Kannegundla et al. (2018) and Omotoso et al. (2019) but lower than 0.137 and 0.107 recorded by Grimal et al. (2012) and El-Aksher et al. (2017). Nevertheless, the range in values obtained for $\mathrm{F}_{\mathrm{ST}}$ indicates moderate to high genetic differentiation among the population studied (El-Aksher et al., 2017). This result also indicated that among/inter-population and within/intra-population variation contributed $6.40 \%$ and $93.60 \%$, respectively. This relative level of variation was further supported by the Analysis of Molecular Variance, AMOVA (Table 1) of the present study. The mean level of gene flow (Nm) among the population (3.933) implied that a low gene flow would not prevent genetic drift, thus enabling the gene differentiation between populations.

The low pairwise $\mathrm{F}_{\mathrm{ST}}$ values among breeds studied inferred that $95.2 \%$ to $95.1 \%$ of the total genetic variation was explained by the individual variability. These values also corroborated AMOVA and F-statistics results obtained in the present study and were in agreement with the report of El-Aksher et al. (2016).

Nei's genetic identity and distances showed lower levels of genetic differentiation partitioned among rabbit populations of South-Eastern Nigeria and suggested the three populations being closely related and had a common ancestor (Abdel-Kafy et al., 2018). This can be verified from Figure 5, which shows the high admixture level of the three breeds and, therefore, pronouncing intra- and inter-breeding among the populations.
Discriminant analysis of Principal Components (DAPC) showed that the admixture level of an individual rabbit among the three breeds was not pure (Figure 5), and this may imply random mating among the three breeds population over time.

The differences obtained in the present study may be attributed to markers sampling error and/or the level of diversity detected, reinforcing against the importance of the number of loci and their coverages of the overall genomes in obtaining reliable characterization of genetic relationship among the population studied.

\section{CONCLUSION}

The Hardy-Weinberg equilibrium (HWE), pairwise genetic differentiation among the population $\left(\mathrm{F}_{\mathrm{ST}}\right)$, Nei's genetic identity, and distances results showed levels of genetic differentiation partitioned among this population and put forward that the three populations study are closely related and had a common ancestor. Also, the polymorphic $(100 \%)$ nature of the 8 microsatellite markers used indicated the suitability of these microsatellites for genetic diversity studies in the rabbit. Hence, a polymorphism that exists among the population studied is more within the breed than among the breed diversity.

\section{CONFLICT OF INTEREST}

The authors wish to declare that no conflict of interest exists.

\section{ACKNOWLEDGEMENT}

This work was financially supported by the TETFund of Nigerian government through Alex Ekwueme Federal University Ndufu- Alike, Ebonyi State. The approval of the Vice Chancellor through 2015 3rd batch TETFund Research Grant committee is gratefully appreciated. 


\section{REFERENCES}

Abdel-Kafy E.M., S. S. Ahmed, A. El-keredy, N. I. Ali, S. Ramadan, \& A. Farid. 2018. Genetic and phenotypic characterization of the native rabbits in Middle Egypt. Vet. World. 11:1120-1126. https://doi.org/10.14202/ vetworld.2018.1120-1126

Adeolu, A. I., F. C. Anosike, R. N. Nwose, N. I. Adeolu, E. Awah, \& E. M. Abiola. 2020. Alleviating micronutrient malnutrition within 1000 days' window period using rabbit (Oryctolagus cuniculus) meat. Pak. J. Nutr. 19:239-244. https://doi.org/10.3923/pjn.2020.239.244

Ben Larbi, M., M. San-Cristobal, C. Chantry-Darmon, \& G. Bolet. 2014. Population structure in Tunisian indigenous rabbit ascertained using molecular information. World Rabbit Sci. 22:223-230. https://doi.org/10.4995/ wrs.2014.1468

Carneiro, M., S. Afonso, A. Geraldes, H. Garreau, G. Bolet, S. Boucher, A. Tircazes, G. Queney, W. Nachman, \& N. Ferrand. 2011. The genetic structure of domestic rabbits. Mol. Biol. Evol. 28:1801-1816. https://doi.org/10.1093/ molbev/msr003

Chantry-Darmon, C., C. Urien, H. De Rochambeau, D. Allain, B. Pena, H. Hayes, C. Grohs, E. P. Cribiu, S. DeretzPicoulet, C. Larzul, J. C. Save, A. Neau, P. Chardon, \& C. Rogel- Gaillard. 2006. A first-generation microsatellite-based integrated genetic and cytogenetic map for the European rabbit (Oryctolagus cuniculus) and localization of angora and albino. Anim. Genet. 37:335-341. https://doi. org/10.1111/j.1365-2052.2006.01462.x

El-Aksher, S. H., H. S. Sherif, M. H. Khalil, H. A. S. El-Garhy, \& S. Ramadan. 2016. Comparative Genetic Analysis among Moshtohor Line Rabbits and Their Parental Lines Using Microsatellite Markers. $3^{\text {rd }}$ International Conference on Biotechnology Applications in Agriculture (ICBAA). Benha University, Moshtohor and Sharm El-Sheikh, Egypt. p. 9-24.

El-Aksher, S.H., H. S. Sherif, M. H. Khalil, H. A. S. El-Garhy, \& S. Ramadan. 2017. Molecular analysis of a new synthetic rabbit line and their parental populations using microsatellite and SNP markers. Gene Rep. 8:17-23. https://doi. org/10.1016/j.genrep.2017.05.001

FAO (Food and Agriculture Organization). 2011. Commission on Genetic Resources For Food and Agriculture: Draft Guidelines on Molecular Genetic Characterization of Animal Genetic Resources. Measurement of Domestic
Animal Diversity (MoDAD)-ISAG/FAO Recommended Microsatellite Markers. Rome, 18-22 July 2011. [ftp://ftp. fao.org/docrep/fao/010/a1404e/a1404e00.pdf]

Frankham, R., D. A. Briscoe, \& J. D. Ballou. 2012. Introduction to Conservation Genetics. Cambridge University Press, Cambridge. https://doi.org/10.1017/CBO9780511809002

Grimal, A., H. M. M.Safaa, M. D. Saenz-de-Juano, M.P. Viudes-de- Castro, G. M. K. Mehaisen, D. A. A. Elsayed, R. Lavara, F. Marco-Jiménez, \& J. S. Vicente. 2012. Phylogenetic relationship among four Egyptian and one Spanish rabbit populations based on microsatellite markers. $10^{\text {th }}$ World Rabbit Congress, Egypt. p. 177-181.

Kannegundla, U., R. S. Sai, P. Amareswari, P. M. Gnana, P. M. \& M. Mahender. 2018. Genetic diversity and phylogenetic relationship analysis of two rabbit breeds by microsatellite markers. J. Anim. Res. 8:289-296. https://doi. org/10.30954/2277-940X.04.2018.19

Nei, M. 1978. Estimation of average heterozygosity and genetic distance from a small number of individuals. Genetics 89:583-590.

Omotoso, A. O., O. Olowofeso, M. Wheto, O. M. Sogunle, O. T. Olufowobi, \& E. T. N. Tor. 2019. Genetic variation amongst four rabbit populations in Nigeria using microsatellite markers. Nigerian Journal of Animal Science 21:37-44.

Rabie, T. S. K. M. 2020. Assessment of genetic variability and population structure of five rabbit breeds by microsatellites markers associated with genes. J. World Poult. Res. 10:125-132. https://doi.org/10.36380/jwpr.2020.17

Rahimi, G., A. Khanahmadi, A. Nejati-Javaremi, \& S. Smailkhanian. 2015. Evaluation of genetic variability in a breeder flock of native chicken based on randomly amplified polymorphic DNA markers. Iran. J. Biotechnol. 3:231-234.

Thimmayya A C. \& S. W. Buskirk. 2012. Genetic connectivity and diversity of pygmy rabbits (Brachylagus idahoensis) in Southern Wyoming. J. Mammal. 93:29-37. https://doi. org/10.1644/11-MAMM-A-045.1

Wu, T., G. Xu, Y. Pan, X. Xie, B. Li, \& X. Wu. 2010. Study on genetic diversity of 7 rabbit populations evidenced by microsatellite makers. J. Anim. Vet. Adv. 9:359-365. https://doi. org/10.3923/javaa.2010.359.365

Zenger, K.R., B. J. Richardson, \& A. M. Vachot-Griffin. 2003. A rapid population expansion retains genetic diversity within European rabbits in Australia. Mol. Ecol. 12:789794. https://doi.org/10.1046/j.1365-294X.2003.01759.x 